\title{
Vasohibin-1 as a novel microenvironmental biomarker for patient risk reclassification in low-risk prostate cancer
}

\author{
Hiroaki Kobayashi, ${ }^{1, *}$, Takeo Kosaka ${ }^{1, *}$, Shuji Mikami ${ }^{2}$, Yasumasa Miyazaki ${ }^{1}$, \\ Kazuhiro Matsumoto ${ }^{1}$, Eiji Kikuchi' ${ }^{1}$, Akira Miyajima ${ }^{1}$, Kaori Kameyama ${ }^{2}$, Yasufumi \\ Sato $^{3}$ and Mototsugu Oya ${ }^{1}$ \\ ${ }^{1}$ Department of Urology, Keio University School of Medicine, Tokyo, Japan \\ ${ }^{2}$ Division of Diagnostic Pathology, Keio University School of Medicine, Tokyo, Japan \\ ${ }^{3}$ Department of Vascular Biology, Institute of Development, Aging and Cancer, Tohoku University, Sendai, Japan \\ *These authors contributed equally to this work \\ Correspondence to: Takeo Kosaka, email: takemduro@gmail.com \\ Keywords: prostate cancer; vasohibin; prostatic biopsy; angiogenesis; immunohistochemistry \\ Received: April 04, $2017 \quad$ Accepted: November 26, $2017 \quad$ Published: December 07, 2017 \\ Copyright: Kobayashi et al. This is an open-access article distributed under the terms of the Creative Commons Attribution License \\ 3.0 (CC BY 3.0), which permits unrestricted use, distribution, and reproduction in any medium, provided the original author and \\ source are credited.
}

\section{ABSTRACT}

Background: We previously reported high expression of vasohibin-1 (VASH1), which is specifically expressed in activated vascular endothelial cells, was a prognostic indicator of disease progression in prostate cancer. The aim of this study was to assess whether VASH1 expression at the area of normal prostatic tissue as well as that of intratumoral tissue could reflect the grade of malignancy of prostate cancer.

Results: Pathological upgrade of Gleason Score $\geq 7$ by radical prostatectomy was observed in 48 patients (upgraded group). The median VASH1 densities of the intratumoral and normal areas were $9.7 \pm 9.5$ and $13.3 \pm 11.8$, respectively, and the median MVDs were $58.6 \pm 20.3$ and $64.1 \pm 23.5$, respectively. We detected a strong positive correlation with each other for both VASH1 density $(\rho=0.589, p<0.001)$ and MVD $(\rho=0.342, p<0.001)$. VASH1 density was significantly higher in the upgreaded group than in the non-upgraded group regardless of prostatic location (intratumoral area: $p<0.001$, normal area: $p<0.001$ ).

Conclusions: Even if the tumor volume was low in biopsy samples, VASH1 density reflected the grade of malignancy throughout the prostate. These results suggested that VASH1 expression could be a novel microenvironmental biomarker for patient risk reclassification in low-risk prostate cancer.

Materials and Methods: Among the 1177 patients who underwent radical prostatectomy, 104 patients diagnosed with Gleason Score $\leq 6$ and positive cores $\leq 3$ were included. We immunohistochemically examined the microvessels positive for anti-CD34 as microvessel density (MVD), and those with activated endothelial cells as VASH1 density using prostatic biopsy samples, and evaluated the association between their expressions and clinicopathological findings.

\section{INTRODUCTION}

Prostate cancer $(\mathrm{PCa})$ is one of the most common types of cancer in men worldwide and its incidence is still increasing due to prostate-specific antigen (PSA) screening, the development of diagnostic imaging system, and innovative ideas of biopsy methods [1-3].
These advancements of diagnostic performance might bring about overdiagnosis by detecting insignificant $\mathrm{PCa}$ that do not require immediate treatment [4]. Thus, nowadays, active surveillance is an accepted management strategy for low-risk $\mathrm{PCa}$, as most of these patients are unlikely to die of $\mathrm{PCa}$ [5]. However, this strategy has some indeterminate factors with risk classification, inclusion 
criteria, and the follow-up schedule that are still based on arbitrary recommendations rather than high-level evidence. Therefore, novel biomarkers that are expressed throughout the prostate, and reflect the malignant potential for high grade and/or invasiveness are highly required.

Angiogenesis, that is the growth of new blood vessels, not only plays a role in human normal development but also in pathophysiological conditions such as inflammation and cancer [6]. Increased vascularity through angiogenesis enhances growth of the primary tumor by supplying nutrients and oxygen, and provides an avenue for hematogenous metastasis [7-9]. One of the most commonly used techniques to quantify intratumoral angiogenesis is microvessel density (MVD) assessment [10]. Some studies indicated that MVD served as a predictor of poorly differentiated PCa and biochemical PSA failure after treatment [11-13]. However, to date evidence of the prognostic role of MVD is contradictory because MVD corresponds to the number of accomplished vessels, including the quiescent vessels. Thus, MVD cannot reflect angiogenic activity alone.

We recently isolated a novel endothelium-derived negative feedback inhibitor or suppressor of angiogenesis, vasohibin-1 (VASH1), which is an intrinsic factor specifically expressed in activated vascular endothelial cells (ECs). VASH1 has been induced by representative angiogenic factors, such as vascular endothelial growth factor (VEGF) and fibroblast growth factor 2 (FGF-2), through PKC $\delta$ [14]. Previous studies found that the expression of VASH1 was restricted to ECs of blood vessels in the tumor stroma, and correlated with the expression of VEGF and FGF-2 in tumor cells [15]. Based on these findings, we also previously reported that high VASH1 expression was a prognostic indicator of disease progression and could serve as a novel biomarker for predicting PCa progression [16].

In the present study, we examined the expression of VASH1 density and MVD using the transrectal needle biopsy (TRNBx) samples in patients with clinically lowrisk PCa. The aim of this study was to determine the strength of a correlation of VASH1 expression as tumor microenvironment between the area of intratumoral and normal tissue, and to assess whether VASH1 expression could reflect the grade of malignancy throughout the prostate.

\section{RESULTS}

\section{Patient characteristics in low-risk PCa}

The patient characteristics and correlation of clinicopathological parameters and VASH1 density or MVD of 104 patients are shown in Table 1. The median age of all patients was $65 \pm 5.7$ years and median PSA level at diagnosis was $6.1 \pm 4.4 \mathrm{ng} / \mathrm{ml}$. Pathological upgrade for GS $\geq 7$ by RP was observed in 48 (46.2\%) patients and stage progression $\geq \mathrm{pT} 3 \mathrm{a}$ was observed in $7(6.7 \%)$ patients. During a median follow-up of 70.2 months, only $7(6.7 \%)$ patients experienced subsequent biochemical PSA recurrence and no one died of PCa.

\section{Evaluation of the difference of VASH1 density and MVD according to prostatic location, and correlation of each clinicopathological feature}

We examined the immunohistochemical expression of VASH1 and CD34 at both of the intratumoral and normal areas to elucidate the biological significance of VASH1 in clinically low-risk PCa (Figures 1, 2). VASH1 staining of vascular ECs was negative or negligible in GS $\leq 6$ cancer (Figures 1B, 2B) while strong VASH1 staining was observed in GS $\geq 7$ cancer in over half of the cases (Figures 1D, 2D).

The median VASH1 density (counts per $\mathrm{mm}^{2}$ ) at the intratumoral and normal areas were $9.7 \pm 9.5$ and 13.3 \pm 11.8 , respectively (Table 1 ). The patients with GS $\geq 7$ by RP had a higher VASH1 density than those with GS $\leq 6$ at both the intratumoral $(p<0.001)$ and normal areas $(p<0.001)$. The level of VASH1 density at the normal area was significantly higher in multiple tumors than solitary tumors $(p=0.004)$. Other clinicopathological factors such as PSA level at diagnosis, clinical and pathological $\mathrm{T}$ stage were not significantly associated with VASH1 density. Meanwhile, the median MVD (counts per $\mathrm{mm}^{2}$ ) at the intratumoral and normal areas were 58.6 \pm 20.3 and $64.1 \pm 23.5$, respectively. There were no significant differences between MVD and clinicopathological factors such as GS by RP, tumor multiplicity, PSA level at diagnosis, and pT stage regardless of prostatic location.

As it has been reported that VASH1 associates with CD34, we also investigated the relationship between VASH1 and CD34 expression. Using the Spearman correlation coefficient test, we detected a significant positive correlation between VASH1 density and MVD at the intratumoral area $(\rho=0.323, p=0.001)$ and at the normal area $(\rho=0.444, p<0.001)$. Moreover, we examined the relationship of VASH1 density and MVD according to the prostatic location focusing on tumor heterogeneity. We detected a strong positive correlation between the intratumoral and normal areas in both VASH1 density $(\rho=0.589, p<0.001)$ and MVD $(\rho=0.342, p<0.001)$.

\section{Clinical value of VASH1 density and MVD in low-risk PCa patients}

We defined the "upgraded group" as the patients whose grade was pathologically upgraded for GS $\geq 7$, in other words unfavorable pathologic findings, and the "non-upgraded group" as not upgraded for GS $\leq 6$ when we divided the patients according to GS by RP. Clinicopathological differences of the two groups are shown in Table 2. The median values of VASH1 density 
Table 1: Correlation of clinicopathological parameters and VASH1 density or MVD in 104 patients

\begin{tabular}{|c|c|c|c|c|c|c|c|c|c|}
\hline & \multirow[b]{2}{*}{$\begin{array}{l}\text { Number of } \\
\text { patients }\end{array}$} & \multicolumn{4}{|c|}{ VASH1 density } & \multicolumn{4}{|c|}{ MVD } \\
\hline & & $\begin{array}{c}\text { Intratumoral } \\
\text { tissue area } \\
(\text { mean } \pm \text { SD) }\end{array}$ & $P$-value & $\begin{array}{c}\text { Normal tissue } \\
\text { area } \\
(\text { mean } \pm \text { SD) }\end{array}$ & $P$-value & $\begin{array}{c}\text { Intratumoral } \\
\text { tissue area } \\
(\text { mean } \pm \mathrm{SD})\end{array}$ & $P$-value & $\begin{array}{c}\text { Normal tissue } \\
\text { area } \\
(\text { mean } \pm \mathrm{SD})\end{array}$ & $P$-value \\
\hline Total & 104 & $9.7 \pm 9.5$ & & $13.3 \pm 11.8$ & & $58.6 \pm 20.3$ & & $64.1 \pm 23.5$ & \\
\hline \multicolumn{10}{|l|}{ Age (years) } \\
\hline$\leq 65$ & $57(54.8 \%)$ & $9.1 \pm 10.1$ & 0.293 & $11.7 \pm 11.5$ & 0.127 & $57.0 \pm 19.7$ & 0.365 & $64.0 \pm 23.4$ & 0.919 \\
\hline$>65$ & $47(45.2 \%)$ & $10.4 \pm 8.7$ & & $15.1 \pm 12.0$ & & $60.6 \pm 21.0$ & & $64.3 \pm 23.9$ & \\
\hline \multicolumn{10}{|c|}{ PSA at diagnosis } \\
\hline$\leq 10.0$ & $86(82.7 \%)$ & $9.7 \pm 9.4$ & 0.896 & $13.0 \pm 11.4$ & 0.779 & $58.3 \pm 20.0$ & 0.780 & $64.9 \pm 24.6$ & 0.542 \\
\hline$>10.0$ & $18(17.3 \%)$ & $9.6 \pm 10.1$ & & $14.6 \pm 13.6$ & & $60.2 \pm 21.9$ & & $60.5 \pm 17.5$ & \\
\hline \multicolumn{10}{|c|}{ Prostate estimation } \\
\hline$\leq 30.0$ & $31(29.8 \%)$ & $9.3 \pm 9.9$ & 0.660 & $11.5 \pm 12.6$ & 0.174 & $59.0 \pm 22.3$ & 0.998 & $62.2 \pm 25.7$ & 0.334 \\
\hline$>30.0$ & $73(70.2 \%)$ & $9.9 \pm 9.4$ & & $14.0 \pm 11.4$ & & $58.4 \pm 19.5$ & & $64.9 \pm 22.7$ & \\
\hline \multicolumn{10}{|l|}{ cT stage } \\
\hline cT1c & $35(33.7 \%)$ & $7.7 \pm 6.8$ & 0.310 & $11.6 \pm 9.9$ & 0.493 & $51.9 \pm 14.1$ & 0.046 & $61.7 \pm 25.3$ & 0.246 \\
\hline cT2 & $69(66.3 \%)$ & $10.8 \pm 10.5$ & & $14.1 \pm 12.6$ & & $62.0 \pm 22.1$ & & $64.9 \pm 22.7$ & \\
\hline \multicolumn{10}{|c|}{ Gleason Score (RP) } \\
\hline$\leq 6$ & $56(53.8 \%)$ & $7.1 \pm 8.0$ & 0.003 & $9.5 \pm 10.9$ & $<0.001$ & $57.2 \pm 19.4$ & 0.432 & $61.8 \pm 22.0$ & 0.417 \\
\hline$\geq 7$ & $48(46.2 \%)$ & $12.7 \pm 10.3$ & & $17.7 \pm 11.4$ & & $60.3 \pm 21.3$ & & $66.8 \pm 25.1$ & \\
\hline \multicolumn{10}{|l|}{ pT stage } \\
\hline$\leq \mathrm{T} 2$ & $97(93.3 \%)$ & $9.6 \pm 9.5$ & 0.701 & $12.8 \pm 11.6$ & 0.434 & $58.7 \pm 20.4$ & 0.491 & $64.2 \pm 23.8$ & 0.519 \\
\hline$\geq \mathrm{T} 3$ & $7(6.7 \%)$ & $11.8 \pm 10.1$ & & $19.4 \pm 13.2$ & & $57.2 \pm 19.3$ & & $62.9 \pm 19.8$ & \\
\hline \multicolumn{10}{|c|}{ Tumor multiplicity } \\
\hline Solitary & $38(36.5 \%)$ & $7.6 \pm 8.1$ & 0.116 & $9.7 \pm 11.5$ & 0.004 & $56.6 \pm 18.3$ & 0.568 & $61.3 \pm 23.4$ & 0.287 \\
\hline Multiple & $66(63.5 \%)$ & $10.9 \pm 10.1$ & & $15.3 \pm 11.5$ & & $59.8 \pm 21.4$ & & $65.8 \pm 23.6$ & \\
\hline \multicolumn{10}{|c|}{ PSA recurrence } \\
\hline No & $97(93.3 \%)$ & $9.8 \pm 9.6$ & 0.772 & $13.3 \pm 11.8$ & 0.990 & $58.1 \pm 20.5$ & 0.217 & $63.4 \pm 24.0$ & 0.109 \\
\hline Yes & $7(6.7 \%)$ & $8.6 \pm 8.7$ & & $12.9 \pm 12.0$ & & $65.5 \pm 17.6$ & & $73.6 \pm 12.4$ & \\
\hline
\end{tabular}

Abbreviations: RP; radical prostatectomy, VASH1; vasohibin-1, MVD; microvessel density.

and MVD were 8.3 and 54.9 per $\mathrm{mm}^{2}$, respectively. We used a median VASH1 density of $\geq 10$ per $\mathrm{mm}^{2}$ and a MVD of $\geq 55$ per $\mathrm{mm}^{2}$ as the cutoff levels. There were no significant differences in patient age, PSA level and MVD at any location. Meanwhile, the upgraded group was significantly higher in cT stage $(p=0.032), \mathrm{pT}$ stage $(p=0.003)$, and VASH1 density at both the intratumoral $(p=0.002)$ and normal areas $(p=0.001)$ than the nonupgraded group.

\section{DISCUSSION}

In the present study, we retrospectively examined the VASH1 and CD34 expression of intratumoral vessels of 104 low-risk PCa patients by immunohistochemical staining using TRNBx and compared it with those of normal prostatic tissue. Although there was a strong positive correlation between the two in both VASH1 density and MVD, VASH1 density was only significantly higher in the upgraded group than that in the nonupgraded group, not only at the intratumoral area but also at the normal area. Meanwhile, MVD had no significant differences.

Current NCCN guidelines and D' Amico classification define the low-risk PCa as clinical T1c-2a, $\mathrm{GS} \leq 6$, and PSA $<10 \mathrm{ng} / \mathrm{ml}[17,18]$. In addition, NCCN guidelines set up very low-risk PCa as clinical T1c, GS $\leq 6$, PSA $<10 \mathrm{ng} / \mathrm{ml}$, number of positive core $<3$, tumor content per positive biopsy core $\leq 50 \%$, and PSA density $<0.15 \mathrm{ng} / \mathrm{ml} / \mathrm{g}$ [17]. Thus, very low-risk PCa emphasized the pathological findings of prostatic biopsy more than low-risk PCa. Even low-risk PCa does not mean complete absence of risk for disease progression and cancer death. However, the majority of newly diagnosed low-risk PCa would undergo definitive therapy, despite the attendant long-term side effects and cost $[19,20]$. A major drawback in the selection of appropriate treatment strategies of low-risk PCa is underestimation of tumor grade or stage at diagnosis. For instance, each positive biopsy core represents only some of the entire prostate, so another high grade or localized invasive PCa may remain elsewhere. 

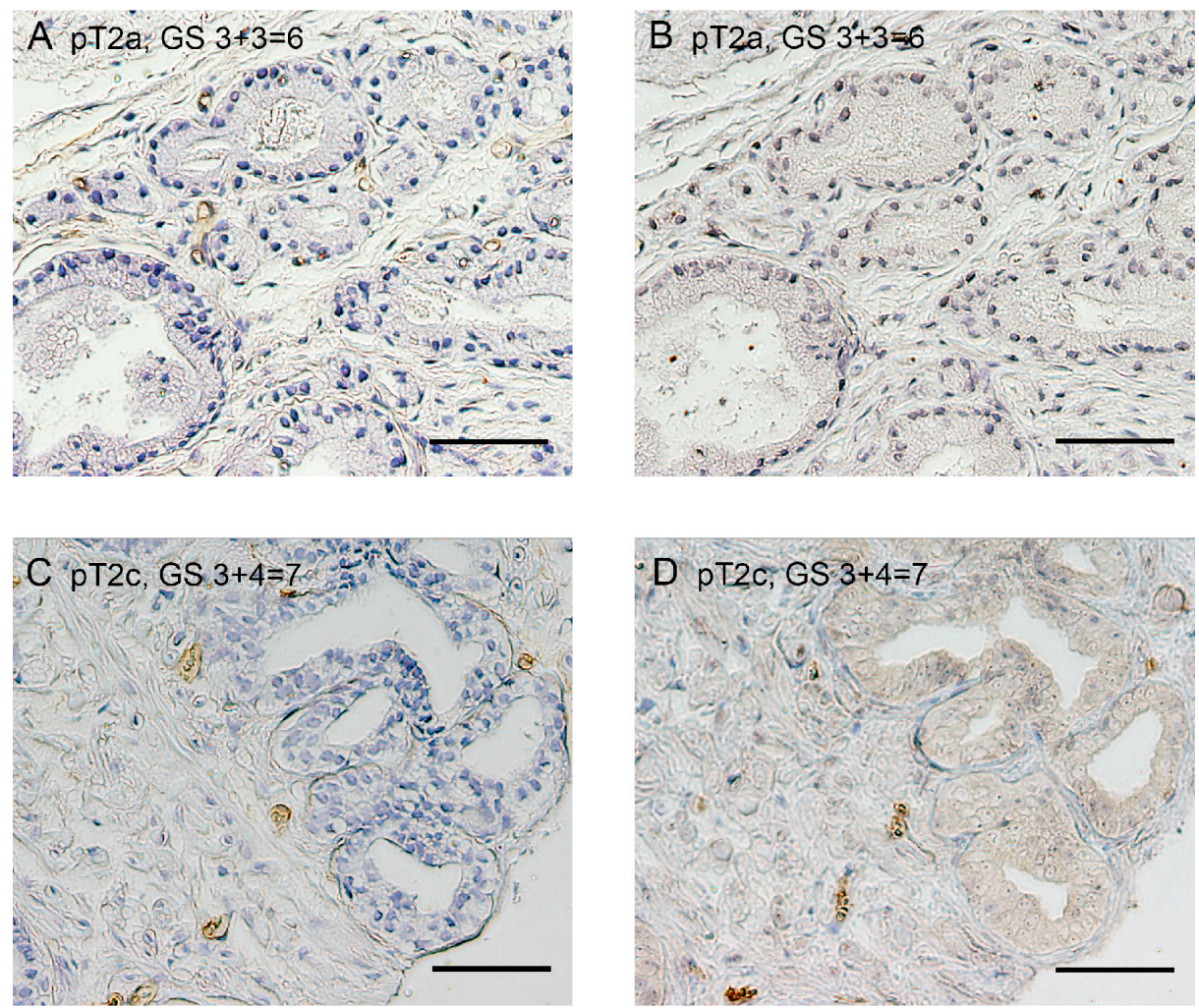

Figure 1: Immunostaining for CD34 (A and C) and VASH1 (B and D) at the intratumoral area in patients with low-risk PCa. Low VASH1 density (A and B) and high VASH1 density (C and D). Bar $=0.1 \mathrm{~mm}$.
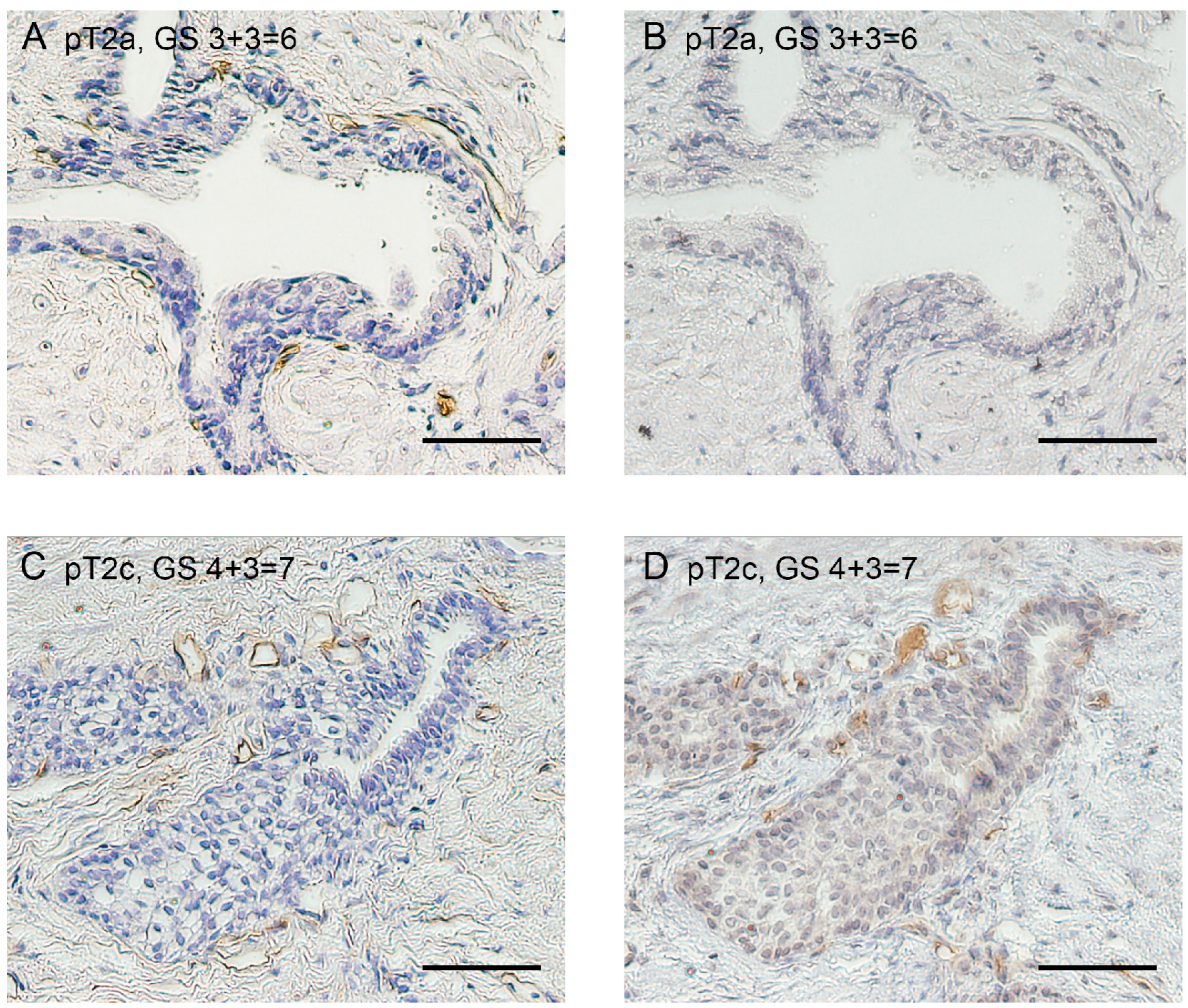

Figure 2: Immunostaining for CD34 (A and C) and VASH1 (B and D) at the normal area in patients with low-risk PCa. Low VASH1 density (A and B) and high VASH1 density (C and D). Bar $=0.1 \mathrm{~mm}$. 
Table 2: Clinicopathological characteristics in 104 patients according to the presence of pathological upgrade

\begin{tabular}{|c|c|c|c|c|}
\hline & Total & $\begin{array}{l}\text { Upgraded } \\
\text { group }\end{array}$ & $\begin{array}{c}\text { Non-upgraded } \\
\text { group }\end{array}$ & $P$-value \\
\hline No. of patients & 104 & 48 & 56 & \\
\hline Median age (range) & $65(49-75)$ & $65(50-74)$ & $65(49-75)$ & \\
\hline$\leq 65$ & 57 & 27 & 30 & 0.784 \\
\hline$>65$ & 47 & 21 & 26 & \\
\hline $\begin{array}{l}\text { Median PSA at diagnosis } \\
\text { (range) }\end{array}$ & $\begin{array}{c}6.1 \\
(3.0-24.9)\end{array}$ & $\begin{array}{c}6.0 \\
(3.0-24.8)\end{array}$ & $\begin{array}{c}6.9 \\
(3.5-24.9)\end{array}$ & \\
\hline$\leq 10.0$ & 86 & 41 & 45 & 0.497 \\
\hline$>10.0$ & 18 & 7 & 11 & \\
\hline \multicolumn{5}{|l|}{ cT stage } \\
\hline cT1c & 35 & 11 & 24 & 0.032 \\
\hline cT2 & 69 & 37 & 32 & \\
\hline \multicolumn{5}{|l|}{ pT stage } \\
\hline$\leq \mathrm{pT} 2$ & 97 & 41 & 56 & 0.003 \\
\hline$\geq \mathrm{pT} 3$ & 7 & 7 & 0 & \\
\hline \multicolumn{5}{|c|}{ MVD at the intratumoral area } \\
\hline$<55$ & 57 & 24 & 33 & 0.362 \\
\hline$\geq 55$ & 47 & 24 & 23 & \\
\hline \multicolumn{5}{|l|}{$\begin{array}{l}\text { VASH1 density } \\
\text { at the intratumoral area }\end{array}$} \\
\hline$<10$ & 60 & 20 & 40 & 0.002 \\
\hline$\geq 10$ & 44 & 28 & 16 & \\
\hline \multicolumn{5}{|c|}{ MVD at the normal tissue area } \\
\hline$<55$ & 41 & 17 & 24 & 0.439 \\
\hline$\geq 55$ & 63 & 31 & 32 & \\
\hline \multicolumn{5}{|l|}{$\begin{array}{l}\text { VASH1 density } \\
\text { at the normal tissue area }\end{array}$} \\
\hline$<10$ & 49 & 14 & 35 & 0.001 \\
\hline$\geq 10$ & 55 & 34 & 21 & \\
\hline
\end{tabular}

Abbreviations: VASH1; vasohibin-1, MVD; microvessel density.

We hypothesized that the key points to calculate the grade of malignancy throughout the prostate was tumor microenvironment, and focused attention on angiogenesis that had a critical role in tumor growth and metastasis. One of the biomarkers that could reflect angiogenic aggressiveness as tumor microenvironment was MVD $[10,13]$. Several studies on PCa indicated that the status of MVD was associated with GS and pathological stage, and could be a prognostic factor of patient survival $[10,12,13,21]$. However, we found no significant association between MVD and pathological upgrade or stage progression in this study. One of the reasons might be because MVD corresponds to the number of accomplished vessels and includes vessels without the potential of neovascularization in tumors.

VASH1 has been isolated from VEGF inducible genes in ECs present in newly formed blood vessels behind the sprouting front where angiogenesis terminates $[22,23]$. We previously reported that VASH1 was specifically expressed in activated vascular ECs and was associated with tumor malignancy such as GS, pT stage, and was an independent predictor of tumor progression in $\mathrm{PCa}$ [16]. Interestingly, that induction of VASH1 disappears under a hypoxic condition or in the presence of inflammatory cytokines [24]. These previous results strongly suggest that the status of VASH1 density could serve as an index of the malignant potential of tumor angiogenesis, and also the level of VASH1 expression might influence unfavorable pathologic findings $[16,25]$.

Indeed, level of VASH1 expression was higher in the upgraded group than the non-upgraded group and had a strong positive correlation with normal prostatic tissue. The results of this study suggest that since high GS tumors caused hyperactivity of angiogenesis throughout 
the prostate, negative cores of TRNBx as well as positive cores might be useful to examine for the grade of tumor malignancy. On the other hand, it has a possibility to miss a vital essentiality of cancer if we pay attention to only detected tumors. The results that VASH1 expression at normal tissue areas in multiple tumors was higher than in solitary tumors, indicated that hyperactivity of angiogenesis might represent the environment of occurrence of the de novo cancer more often anywhere.

Several limitations of our study should be considered. First and foremost, it was performed in a retrospective manner with a limited number of patients. Another limitation was that we did not perform MRI for all cohorts, which could have affected the diagnostic performance of PCa.

\section{CONCLUSIONS}

Our results demonstrate that high VASH1 expression in positive cores as well as negative cores reflected unfavorable pathological findings in clinically low-risk PCa. These results indicate that VASH1 expression could be a novel microenvironmental biomarker for patient risk reclassification in localized $\mathrm{PCa}$.

\section{MATERIALS AND METHODS}

\section{Patient selection}

We retrospectively analyzed the clinical records of 1177 patients who underwent laparoscopic radical prostatectomy (RP) at Keio University Hospital between January 2003 and January 2015. Among them, 104 patients who underwent TRNBx at our own hospital and were diagnosed with localized PCa with a Gleason score (GS) of $\leq 6$, total positive cores $\leq 3$, and $\leq 50 \%$ tumor content per positive biopsy core were included. None of the patients had received neoadjuvant hormonal treatment before RP. This retrospective clinical study was approved by the ethical committee of Keio University Hospital. The clinical characteristics of all cohorts are shown in Table 1. Clinical $\mathrm{T}$ stage was assessed by digital rectal examination (DRE) and magnetic resonance imaging (MRI), and cT2 was defined when the tumor was palpable or visible on imaging while cT1c was defined as negative DRE and the absence of suspicious lesions by MRI. Patients were followed by serum PSA level and imaging studies after RP. Biochemical PSA recurrence was defined by an elevation of serum PSA level at three consecutive measurements.

\section{Tissue samples and immunohistochemistry}

All pathological specimens were re-reviewed by dedicated uropathologists to unify the reproducibility of the diagnosis. As for the pathologic stage, all tumors were classified according to the 2006 TNM staging system. We carried out immunohistochemical staining for CD34 (as a marker of vascular ECs) and VASH1. All specimens were fixed in $10 \%$ formalin, embedded in paraffin, and cut into $4 \mu \mathrm{m}$ thick sections and placed on silane-coated glass slides. Tissue sections were deparafinized in xylene, and hydrated by immersion in graded alcohols and finally in distilled water. After antigen retrieval was performed, endogenous peroxidase activity was blocked by $0.3 \%$ hydrogen peroxidase. The tissue sections were then incubated with a blocking solution of $6 \%$ dry milk in PBS. The primary antibodies were all mouse monoclonal antibodies (mAbs): anti-human VASH1 mAb diluted at a concentration of $4 \mu \mathrm{g} / \mathrm{ml}$ and anti-CD34 (Nichirei Biosciences, Tokyo, Japan).

We previously described a mouse mAb against a synthetic peptide corresponding to the 286 to 299

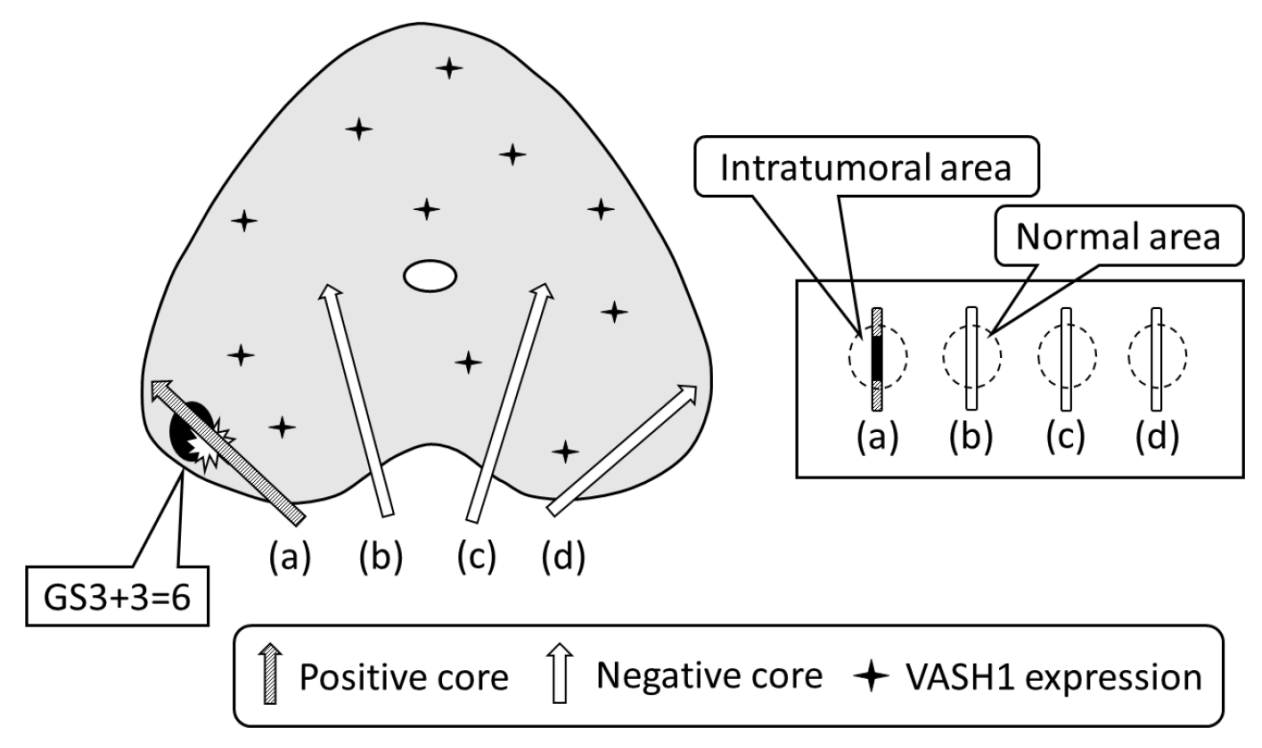

Figure 3: The total image of prostate cancer with tumor microenvironment and definition of the "intratumoral area" and "normal area". 
amino acid sequence of VASH1 [25]. After washing with PBS, the tissue sections were incubated with secondary antibodies (Histofine Simple Stain MAX PO (M); Nichirei Biosciences). Color was developed with 3, $3^{\prime}$-diaminobenzamine tetrahydrochloride in $50 \mathrm{mmol} / \mathrm{L}$ Tris- $\mathrm{HCl}(\mathrm{pH} 7.5)$ containing $0.005 \%$ hydrogen peroxide. The sections were counterstained with haematoxylin. The positive control slide CD34 antigen was prepared from paraffin-fixed bladder cancer tissue with high MVD. The appropriate negative controls slides for CD34 antigen and VASH1 were prepared by substituting the primary antibody with the immune globulin fraction of nonimmune mouse serum at the same concentration in each staining run.

\section{Evaluation of immunostaining}

Two authors independently evaluated immunoreactivity. They were blinded to the clinical course of the patients and the average of the numbers counted by the 2 investigators was used for subsequent analyses. Olympus IX71 (Olymus, Tokyo, Japan) was used for the analysis. We counted the microvessels at the neighborhood of cancer in positive cores as the "intratumoral area" and at the normal tissue which included the largest possible number of ductuli separately in negative cores as the "normal area" (Figure 3). Microvessels were identified on the basis of their architecture, lumen lined by ECs, complemented by positivity of the ECs for anti-CD34 after scanning the immunostained section at low magnification $(\times 40$ and $\times 100)$. The areas with the highest number of distinctly highlighted microvessels were selected and counted at high magnification $(\times 200)$. Any immunostained EC or cluster separated from adjacent vessels was counted as a single microvessel, even in the absence of vessel lumen. Each single count was defined as the highest number of microvessels identified at the "hot spot" as shown previously [13, 26-28]. The highest number of microvessels in the hot spot was counted for MVD. VASH1-positive signals were counted in the "hot spot" in which the highest number of vessels positive for anti-CD34 was identified. We regarded the number of VASH1-positive signals per $\mathrm{mm}^{2}$ as "VASH1 density" [28-30].

\section{Statistical analysis}

The associations between each clinicopathological parameter and VASH1 density or MVD of each location were validated using $\chi^{2}$ test or Mann-Whitney $U$-test. Differences among groups were regarded as significant when $P<0.05$. These analyses were conducted with the SPSS version 22.0 statistical software package.

\section{Abbreviations}

PCa: prostate cancer; PSA: prostate-specific antigen; MVD: microvessel density; ECs: endothelial cells; VASH1: vasohibin-1; VEGF: vascular endothelial growth factor; FGF-2: fibroblast growth factor 2; TRNBx: transrectal needle biopsy; RP: radical prostatectomy; GS: Gleason score; DRE: digital rectal examination; MRI: magnetic resonance imaging; mAbs: monoclonal antibodies.

\section{ACKNOWLEDGMENTS}

We thank colleagues from the Department of Vascular Biology, Institute of Development, Aging and Cancer, Tohoku University for their excellent technical assistance in purifying anti-human VASH1 mAB. This work was supported in part by a Grant-in-Aid for Young Scientists (\#10598428 to Hiroaki Kobayashi) from the Ministry of Education, Culture, Sports, Science and Technology of Japan. This work was also supported in part by the Joint Research Program of Joint Usage/Research Center at the Institute of Development, Aging and Cancer, Tohoku University.

\section{CONFLICTS OF INTEREST}

The authors declare no conflicts of interest.

\section{REFERENCES}

1. Sivaraman A, Sanchez-Salas R, Barret E, Ahallal Y, Rozet F, Galiano M, Prapotnich D, Cathelineau X. Transperineal template-guided mapping biopsy of the prostate. Int J Urol. 2015; 22:146-151.

2. Gayet M, van der Aa A, Beerlage HP, Schrier BP, Mulders PF, Wijkstra $H$. The value of magnetic resonance imaging and ultrasonography (MRI/US)-fusion biopsy platforms in prostate cancer detection: a systematic review. BJU Int. 2016; 117:392-400.

3. Siegel RL, Miller KD, Jemal A. Cancer statistics, 2016. CA Cancer J Clin. 2016; 66:7-30.

4. Alberts AR, Schoots IG, Roobol MJ. Prostate-specific antigen-based prostate cancer screening: Past, future. Int J Urol. 2015; 22:524-532.

5. Wilt TJ, Brawer MK, Jones KM, Barry MJ, Aronson WJ, Fox S, Gingrich JR, Wei JT, Gilhooly P, Grob BM, Nsouli I, Iyer $\mathrm{P}$, Cartagena $\mathrm{R}$, et al, and Prostate Cancer Intervention versus Observation Trial (PIVOT) Study Group. Radical prostatectomy versus observation for localized prostate cancer. N Engl J Med. 2012; 367:203-213.

6. Sato Y. Molecular diagnosis of tumor angiogenesis and anti-angiogenic cancer therapy. Int J Clin Oncol. 2003; 8:200-206.

7. Folkman J. How is blood vessel growth regulated in normal and neoplastic tissue? G.H.A. Clowes memorial Award lecture. Cancer Res. 1986; 46:467-473.

8. Kemik O, Kemik SA, Purysa S, Tuzun S. Imbalance of VEGF family serum levels and receptors in patients with 
inflammatory bowel disease. Bratisl Lek Listy. 2010; 111:439-442.

9. Folkman J. What is the evidence that tumors are angiogenesis dependent? J Natl Cancer Inst. 1990; 82:4-6.

10. Weidner N, Semple JP, Welch WR, Folkman J. Tumor angiogenesis and metastasis - correlation in invasive breast carcinoma. N Engl J Med. 1991; 324:1-8.

11. Weidner N, Carroll PR, Flax J, Blumenfeld W, Folkman J. Tumor angiogenesis correlates with metastasis in invasive prostate carcinoma. Am J Pathol. 1993; 143:401-409.

12. Josefsson A, Wikstrom P, Granfors T, Egevad L, Karlberg L, Stattin P, Bergh A. Tumor size, vascular density and proliferation as prognostic markers in GS 6 and GS 7 prostate tumors in patients with long follow-up and noncurative treatment. Eur Urol. 2005; 48:577-583.

13. Kosaka T, Miyajima A, Takayama E, Kikuchi E, Nakashima J, Ohigashi T, Asano T, Sakamoto M, Okita H, Murai M, Hayakawa M. Angiotensin II type 1 receptor antagonist as an angiogenic inhibitor in prostate cancer. Prostate. 2007; 67:41-49.

14. Shimizu K, Watanabe K, Yamashita H, Abe M, Yoshimatsu H, Ohta H, Sonoda H, Sato Y. Gene regulation of a novel angiogenesis inhibitor, vasohibin, in endothelial cells. Biochem Biophys Res Commun. 2005; 327:700-706.

15. Hosaka T, Kimura H, Heishi T, Suzuki Y, Miyashita H, Ohta H, Sonoda H, Moriya T, Suzuki S, Kondo T, Sato Y. Vasohibin-1 expression in endothelium of tumor blood vessels regulates angiogenesis. Am J Pathol. 2009; 175:430-439.

16. Kosaka T, Miyazaki Y, Miyajima A, Mikami S, Hayashi Y, Tanaka N, Nagata H, Kikuchi E, Nakagawa K, Okada Y, Sato Y, Oya M. The prognostic significance of vasohibin-1 expression in patients with prostate cancer. Br J Cancer. 2013; 108:2123-2129.

17. Mohler JL, Armstrong AJ, Bahnson RR, D'Amico AV, Davis BJ, Eastham JA, Enke CA, Farrington TA, Higano CS, Horwitz EM, Hurwitz M, Kane CJ, Kawachi MH, et al. Prostate Cancer, Version 1.2016. J Natl Compr Canc Netw. 2016; 14:19-30.

18. D'Amico AV, Whittington R, Malkowicz SB, Schultz D, Blank K, Broderick GA, Tomaszewski JE, Renshaw AA, Kaplan I, Beard CJ, Wein A. Biochemical outcome after radical prostatectomy, external beam radiation therapy, or interstitial radiation therapy for clinically localized prostate cancer. JAMA. 1998; 280:969-974.

19. Cooperberg MR, Vickers AJ, Broering JM, Carroll PR. Comparative risk-adjusted mortality outcomes after primary surgery, radiotherapy, or androgen-deprivation therapy for localized prostate cancer. Cancer. 2010; 116:5226-5234.

20. Mahmood U, Levy LB, Nguyen PL, Lee AK, Kuban DA, Hoffman KE. Current clinical presentation and treatment of localized prostate cancer in the United States. J Urol. 2014; 192:1650-1656.

21. Bettencourt MC, Bauer JJ, Sesterhenn IA, Connelly RR, Moul JW. CD34 immunohistochemical assessment of angiogenesis as a prognostic marker for prostate cancer recurrence after radical prostatectomy. J Urol. 1998; 160:459-465.

22. Shibuya T, Watanabe K, Yamashita H, Shimizu K, Miyashita H, Abe M, Moriya T, Ohta H, Sonoda H, Shimosegawa T, Tabayashi K, Sato Y. Isolation and characterization of vasohibin-2 as a homologue of VEGF-inducible endothelium-derived angiogenesis inhibitor vasohibin. Arterioscler Thromb Vasc Biol. 2006; 26:1051-1057.

23. Sato Y, Sonoda $H$. The vasohibin family: a negative regulatory system of angiogenesis genetically programmed in endothelial cells. Arterioscler Thromb Vasc Biol. 2007; 27:37-41.

24. Sato Y. The vasohibin family: a novel family for angiogenesis regulation. J Biochem. 2013; 153:5-11.

25. Watanabe K, Hasegawa Y, Yamashita H, Shimizu K, Ding Y, Abe M, Ohta H, Imagawa K, Hojo K, Maki H, Sonoda $\mathrm{H}$, Sato Y. Vasohibin as an endothelium-derived negative feedback regulator of angiogenesis. J Clin Invest. 2004; 114:898-907.

26. Miyazaki Y, Kosaka T, Mikami S, Kikuchi E, Tanaka N, Maeda T, Ishida M, Miyajima A, Nakagawa K, Okada Y, Sato Y, Oya M. The prognostic significance of vasohibin-1 expression in patients with upper urinary tract urothelial carcinoma. Clin Cancer Res. 2012; 18:4145-4153.

27. Mikami S, Oya M, Mizuno R, Murai M, Mukai M, Okada Y. Expression of Ets-1 in human clear cell renal cell carcinomas: implications for angiogenesis. Cancer Sci. 2006; 97:875-882.

28. Yoshinaga $\mathrm{K}$, Ito $\mathrm{K}$, Moriya $\mathrm{T}$, Nagase $\mathrm{S}$, Takano $\mathrm{T}$, Niikura H, Sasano H, Yaegashi N, Sato Y. Roles of intrinsic angiogenesis inhibitor, vasohibin, in cervical carcinomas. Cancer Sci. 2011; 102:446-451.

29. Tamaki K, Sasano H, Maruo Y, Takahashi Y, Miyashita M, Moriya T, Sato Y, Hirakawa H, Tamaki N, Watanabe M, Ishida T, Ohuchi N. Vasohibin-1 as a potential predictor of aggressive behavior of ductal carcinoma in situ of the breast. Cancer Sci. 2010; 101:1051-58.

30. Tamaki K, Moriya T, Sato Y, Ishida T, Maruo Y, Yoshinaga K, Ohuchi N, Sasano H. Vasohibin-1 in human breast carcinoma: a potential negative feedback regulator of angiogenesis. Cancer Sci. 2009; 100:88-94. 